Type of the Paper (Article.)

\title{
Analysis of Transient Voltage Problem Caused by Electric Arc Furnace
}

\author{
Liu Yang ${ }^{1}$, Qinyue Tan ${ }^{1, *}$ and Di Xiong ${ }^{1}$ \\ 1 College of Water Resources and Architectural Engineering, Northwest A\&F University, Shaanxi 712100, \\ China; yl1195431826@163.com (L.Y); 18821712577@163.com (D.X); \\ 2 *Correspondence: qinyuetan@nwsuaf.edu.cn ;
}

\begin{abstract}
Three-phase AC electric arc furnace (EAF) is a typical non-linear load, causing many power quality problems. Most of the researches on the voltage problems of EAF mainly focus on the voltage fluctuation, and less on the transient voltage problems caused by EAF short circuit and open circuit. In this paper, the relationship between voltage and current of EAF is obtained by combining hyperbolic function and exponential function, then the white noise and chaotic circuit are added to establish the EAF model which is suitable for the study of voltage fluctuation and transient voltage. This paper analyzes the causes of the transient voltage problem of the EAF, calculates the short-circuit current, reactive impact and the influence on voltage at the point of common coupling (PCC) in the three-phase short-circuit of the EAF, and compares the calculation results with the simulation results to prove the accuracy of this model. The results show that the reactive impact of three-phase short circuit is about twice as much as that of normal operation of EAF, resulting in about $30 \%$ voltage sag at the PCC, which is very unfavorable to the power grid. This paper provides reference for transient power quality evaluation and dynamic reactive power compensation of EAF.
\end{abstract}

Keywords: Electric arc furnace; Arc short circuit; transient power quality; transient voltage; voltage sag

\section{Introduction}

Non-linear load is the main pollution source of power quality. Among many nonlinear loads, AC electric arc furnace (EAF) is the most complicated and most random pollution source. The voltage fluctuation, harmonic, three-phase unbalance and other power quality problems caused by EAF have been the focus of research [1-4]. For voltage problems of EAFs, in the initial stage of melting, the unstable arc combustion causes power fluctuations and then causes the arc voltage fluctuations. In the later stage of melting, metal block collapse often occurs in the electric arc furnace, leading to short circuit of the electrode, which causes transient power quality problems such as reactive power impact, voltage swell and voltage sag. In the research of electric arc furnace voltage, there are more researches on arc voltage fluctuations [5-7], but less research on transient voltage problems such as voltage swell and voltage sag. This paper will establish a model suitable for studying the transient voltage of EAFs, simulate and analyze the voltage sag of EAF caused by short circuits.

The arc resistance of EAF is nonlinear time-varying resistance, so it is difficult to model the EAF accurately. Many literatures have studied the EAF model [8-10], but none of them has been widely accepted. At present, the modeling methods of EAF can be divided into three categories roughly. The first based on the physical mechanism during the operation of the electric arc furnace, studies the internal and external factors that affect the arc resistance, and obtains the expression of arc resistance [11,12]. The second is to find out the relationship between arc voltage and arc current. The third is to list the differential equations based on the law of conservation of energy of the electric arc furnace to establish 
the electric arc furnace model [13-15]. There are generally two methods in the second category to find the relationship between arc voltage and arc current. One is to fit and simplify the volt-ampere characteristic curve of the EAF to obtain the expression of the arc voltage respect to the arc current, and used the current control voltage source to simulate the EAF [16-18]. The second is to use hyperbolic function, exponential function or a combination of two functions to express the relationship between electric arc furnace voltage and current $[19,20]$. In addition, there are some other modeling methods, such as harmonic voltage source and harmonic current source model that are only suitable for harmonic research of EAF and neural network modeling [21-23].

A good EAF model should meet the requirements of simple method, high precision, good portability and not too much initial conditions. In this paper, the hyperbolic model and the exponential model are combined to obtain the relationship between the voltage and current of the EAF to establish a static model of the EAF. White noise is added to simulate the random change of the arc. At the same time, the electric arc voltage is modulated by Chua's chaotic circuit to obtain the final EAF model. Compared with other models, this model reflects the volt-ampere characteristics of EAF more simply and accurately. At the same time, two modules of random change of arc and chaos are added to simulate arc voltage changes. Therefore, it is not only suitable for studying electric arc furnace voltage fluctuations, but also for studying e the transient voltage of the EAF. The transient voltage problem. And use the established EAF model to analyze the voltage sag problem when three-phase short circuit occurs.

\section{Transient Voltage Model of Arc Furnace}

According to the combustion state of the arc, the EAF can be divided into three stages: the arc forming stage, the arc combustion stage and the arc extinguishing stage. In the electric arc forming stage, the arc changes from the extinguishing state to the burning state, the arc voltage rises from zero to the reignition voltage, and the electric arc ignites and enters the combustion stage. When the electric arc length is fixed in the stage, the relationship between arc voltage and arc current can be described by a hyperbolic function [19-20]:

$$
u(i)=V_{0}+\left(\frac{C}{D+i}\right),
$$

$V_{0}$ is the threshold magnitude to which the electric arc voltage approaches as current increases, it is related to the arc length. The constants $C$ and $D$ are related to arc power and arc current, respectively.

After the arc voltage drops to the arc extinguishing voltage, the arc is extinguished, the EAF enters the arc extinguishing stage, and the arc voltage and current both drop to zero. The relationship between arc voltage and arc current in the arc extinguishing stage is described by exponential function [19-20]:

$$
u(i)=\left\{\begin{array}{ll}
V_{0}\left(1-e^{-i / \tau}\right), & \mathrm{i} \geq 0 \\
-V_{0}\left(1-e^{i / \tau}\right), & \mathrm{i}<0
\end{array},\right.
$$

$\tau$ is a current constant used to simulate the steepness of the positive and negative phases of the arc current.Therefore, the relationship between arc voltage and arc current is: 


$$
u(i)=\left\{\begin{array}{ll}
V_{0}+\left(\frac{C_{a}}{D+i}\right) & \frac{d i}{d t} \geq 0, i \geq 0 \\
V_{0}\left(1-e^{-i / \tau}\right) & \frac{d i}{d t}<0, i \geq 0 \\
-V_{0}+\left(\frac{C_{b}}{i-D}\right) & \frac{d i}{d t}>0, i \leq 0 \\
-V_{0}\left(1-e^{i / \tau}\right) & \frac{d i}{d t}<0, i<0
\end{array},\right.
$$

the EAF volt-ampere characteristic curve is shown in Figure 1.

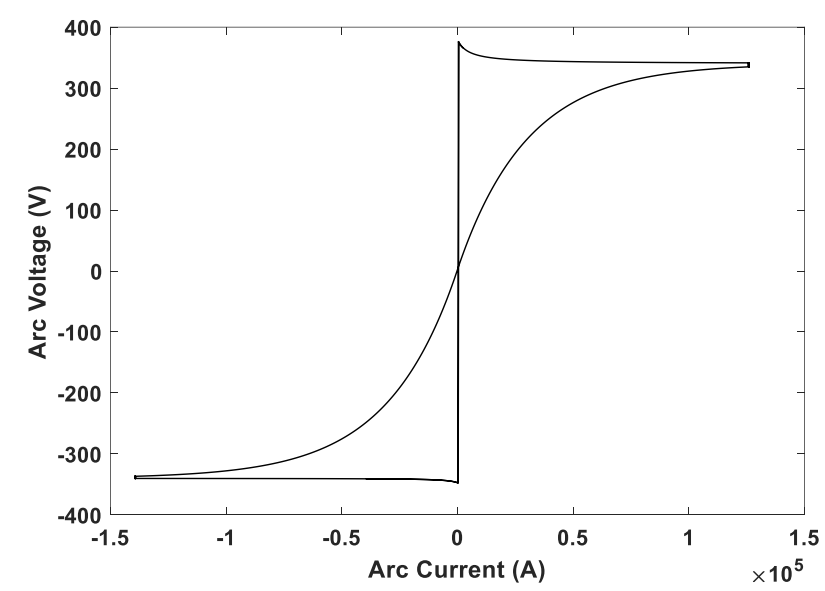

Figure 1. The V-I characteristic curve of Electric arc furnace

Equation (3) describes the relationship between arc voltage and arc current under the condition of a certain arc length. However, during the normal operation of the EAF, because the surface of the slag smelted by the EAF is uneven, the arc length is constantly changing. Variations in arc length cause arc voltage fluctuations. The relationship between arc length and arc voltage is expressed by equation (4):

$$
V_{0}=a+b l,
$$

In equation (4), $l$ is the arc length. a is the sum of the potential drops in the anode and cathode regions, taking $a=40 \mathrm{~V}, b$ is the potential gradient in the arc column, $b=10 \mathrm{~V} / \mathrm{cm}$. The change of arc length is random, and white noise is used to simulate the random change of arc length.

$$
l=l_{0}(1+m N(t)),
$$

$l_{0}$ fluctuates between $5 \mathrm{~cm}$ and $30 \mathrm{~cm}$ during the melting period. Here, the value of $l_{0}$ is $25 \mathrm{~cm}$. In actual operation, the load of the three-phase EAF is asymmetrical. Different $l_{0}$ can be set to simulate the situation of asymmetrical three-phase EAF load. $N(t)$ is bandlimited white noise.

In previous research, the voltage change of the EAF was proved to be chaotic, so the low-frequency chaotic signal generated by the chaotic circuit was used to modulate the arc voltage, and then the final dynamic model of the EAF was obtained.

$$
v(t)=v\left(1+n v_{\text {chaotic }}\right),
$$

$n$ is the ratio of the peak value of the low-frequency voltage chaotic signal to the peak value of the arc voltage. The chaotic signal is simulated by Chua's circuit with asymmetric nonlinear resistance. Chua's circuit is the smallest and simplest third-order autonomous 
circuit that can produce chaotic behavior [15]. Chua's chaotic circuit diagram is shown in Figure 2.

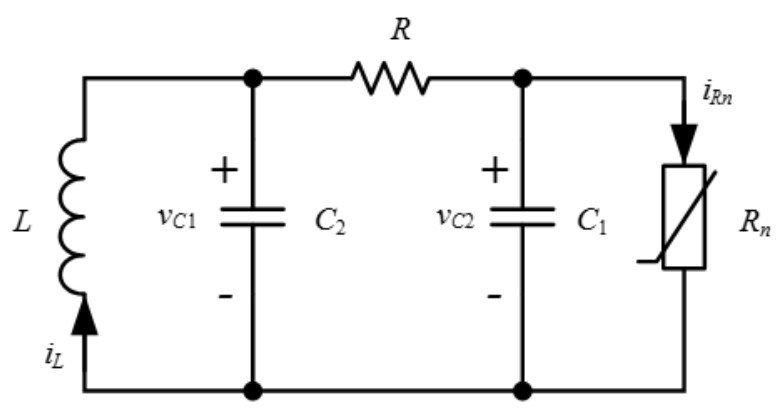

Figure 2. The circuit diagram of chua's chaotic

The circuit equation is as (7):

$$
\left\{\begin{aligned}
C_{1} \frac{d v_{c 1}}{d t} & =\frac{v_{c 2}-v_{c 1}}{R}-i_{R_{n}} \\
C_{2} \frac{d v_{c 2}}{d t} & =i_{L}-\frac{v_{c 2}-v_{c 1}}{R} \\
L \frac{d i_{L}}{d t} & =-v_{c 2}
\end{aligned}\right.
$$

Figure 3 is the simulation waveform of arc voltage and arc current after adding white noise and chaos. We can see from the figure that the arc voltage during the melting period is similar to a square wave with obvious random fluctuations. The voltage waveform, current waveform and simulated volt-ampere characteristic curve are similar to those in the actual operation process, indicating that the model can accurately simulate for EAF. Different electric arc furnaces can be simulated by changing the parameters in the relationship between arc voltage and current.

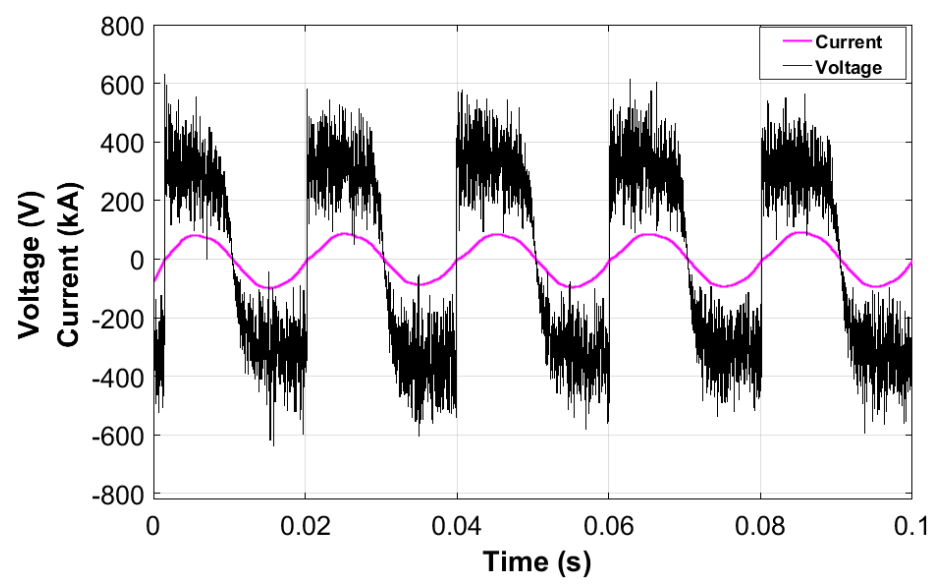

Figure 3. The waveform of arc voltage and arc current

\section{Analysis of EAF Short Circuit}

Figure 4 is a single-phase power supply circuit diagram of an EAF, where $r_{1}$ and $x_{1}$ are the resistance and reactance between the power supply and the primary side of the auxiliary transformer, $r_{2}$ and $x_{2}$ are the resistance and reactance between the secondary side of the auxiliary transformer and the primary side of the furnace transformer, $r_{\mathrm{d}}, x_{\mathrm{d}}$ are the resistance and reactance of the EAF short network, $r, x$ are the resistance and reactance of the EAF short network, $U, U_{1}$, and $U_{2}$ are the power supply voltage, the secondary side voltage of the auxiliary transformer, and the secondary side voltage of the furnace 
transformer respectively. The parameters of the EAF power supply system are shown in Table 1.

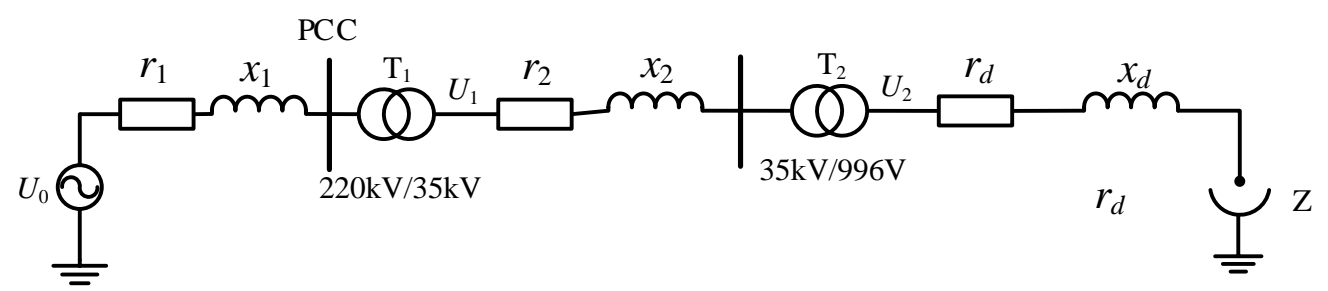

Figure 4. Single-phase power supply system circuit diagram of an EAF

Table 1. The parameters of EAF power supply system

\begin{tabular}{cc}
\hline Component parameter & The numerical \\
\hline mains voltage $U_{0} / \mathrm{kV}$ & 220 \\
line reactance $X_{\mathrm{L} 1} / \Omega$ & 1.452 \\
voltage level of auxiliary transformer & $220 \mathrm{kV} / 35 \mathrm{kV}$ \\
auxiliary transformer capacity / MVA & 130 \\
line reactance $X_{\mathrm{L} 2} / \Omega$ & 2.4017 \\
voltage level of furnace transformer & $35 \mathrm{kV} / 996 \mathrm{~V}$ \\
furnace transformer capacity $/ \mathrm{MVA}$ & 90 \\
short network resistance $/ \mathrm{m} \Omega$ & $\mathrm{r}_{\mathrm{d}}=0.4077$ \\
& $\mathrm{Xd}_{\mathrm{d}}=2.9786$ \\
\hline
\end{tabular}

Arc voltage derivation to Arc current to obtain arc impedance Z. Equation 8 is the arc impedance expression of the static model, figure 5 is the arc impedance curve of the static model.

$$
Z= \begin{cases}-\frac{C_{a}}{(D+i)^{2}} & \frac{d i}{d t} \geq 0, i \geq 0 \\ \frac{V_{0}}{\tau} e^{-i / \tau} & \frac{d i}{d t}<0, i \geq 0 \\ -\frac{C_{a}}{(i-D)^{2}} & \frac{d i}{d t}>0, i \leq 0 \\ \frac{V_{0}}{\tau} e^{i / \tau} & \frac{d i}{d t}<0, i<0\end{cases}
$$

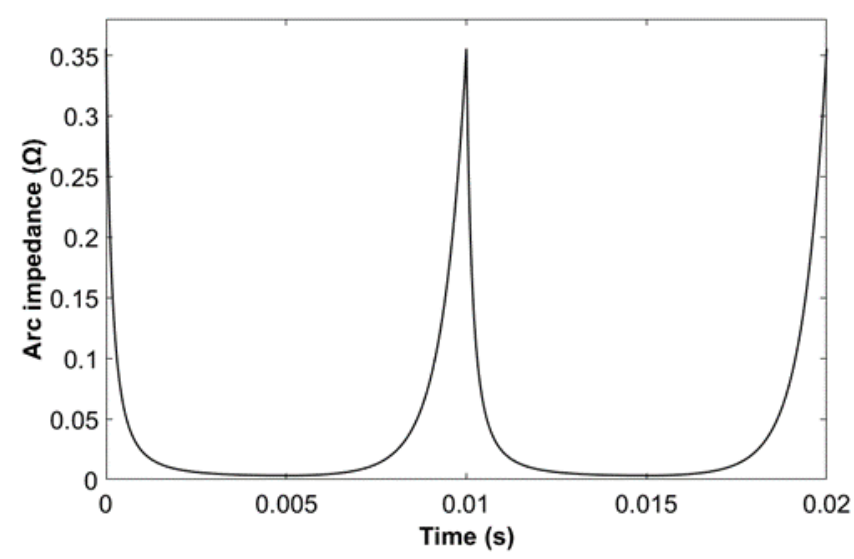

Figure 5. The curve of arc impedance

Arc furnace resistance: $r=|Z| \cdot \cos \varphi$, 
Arc furnace reactance $: x=|Z| \cdot \sin \varphi$,

Arc current: $I_{h}=\frac{U_{2} / \sqrt{3}}{\sqrt{\left(r_{0}+r_{d}+r\right)^{2}+\left(x_{0}+x_{d}+x\right)^{2}}}$,

Reactive power: $Q=I_{h}^{2} \cdot\left(x_{0}+x_{d}+x\right)$,

Active power: $P=I_{h}^{2} \cdot\left(r+r_{0}+r_{d}\right)$ ，

Power factor: $\cos \varphi=\frac{r+r_{0}+r_{d}}{r+r_{0}+r_{d}+x_{0}+x_{d}+x}$,

When the electrode of the EAF contacts with the furnace material and causes a short circuit, the reactive power increases sharply, and the active power decreases rapidly, resulting in a large current inrush, serious circuit loss and voltage sag. After a short circuit occurs, the electrode adjustment system will adjust the position of the electrode to restore the operation of the EAF. Generally, the duration of a short-circuit fault in the EAF is $0.01 \mathrm{~s}$ to $0.02 \mathrm{~s}$. The most serious short-circuit situation in EAF should be the simultaneous shortcircuit of the three-phase electrodes. Of course, the probability of three-phase simultaneous short circuit in modern EAF is relatively small, but due to the serious situation, it cannot be ignored.

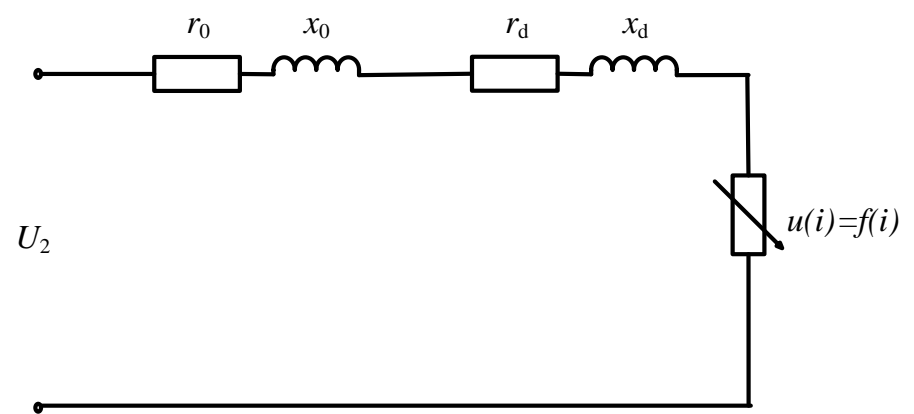

Figure 6. Equivalent circuit diagram

Figure 4can be equivalent to Figure 6. $r_{0}$ and $x_{0}$ are the resistance and reactance of the line resistance and reactance before the furnace transformer converted to the secondary side of the furnace transformer. When a three-phase short circuit occurs in an EAF, the EAF is three-phase symmetrical, and the short circuit parameters of one phase circuit are:

Short circuit current: $I^{\prime}=\frac{U_{2} / \sqrt{3}}{\sqrt{\left(r_{0}+r_{d}\right)^{2}+\left(x_{0}+x_{d}\right)^{2}}}$,

Reactive shock: $Q^{\prime}=I^{\prime 2} \cdot\left(x_{0}+x_{d}\right)$,

Active shock: $P^{\prime}=I^{\prime 2} \cdot\left(r_{0}+r_{d}\right)$,

Table 2 shows the calculation results when a three-phase short circuit occurs in an EAF.

Table 2. The calculation results when a three-phase short circuit occurs in an EAF

\begin{tabular}{cccc}
\hline Position & Short circuit current/kA & Reactive power/MW & Active power/MVar \\
\hline secondary side of furnace transformer & 98.67 & & \\
$35 \mathrm{kV}$ side & 2.81 & 68.15 & 214.19 \\
$220 \mathrm{kV}$ side & 0.447 & & \\
\hline
\end{tabular}

\section{MATLAB Simulink Verification Results}

The parameters of the EAF power supply system are shown in Table 1. The normal operation of the electric arc furnace EAF and the three-phase short circuit are simulated using the model built in this paper. Table 3 is the parameters of the EAF during normal operation, Table 4 is the simulation results when a three-phase short circuit occurs in an EAF, Figure 7 shows the waveforms of voltage, current, and active power and reactive 
power at the PCC when a three-phase short circuit occurs in an EAF at 0.05 s to $0.06 \mathrm{~s}$ and $0.1 \mathrm{~s}$ to $0.12 \mathrm{~s}$.

Table 3. The parameters of EAF during normal operation

\begin{tabular}{|c|c|c|}
\hline Position & voltage $/ \mathbf{k V}$ & current/kA \\
\hline Primary side of auxiliary transformer & 217 & 0.347 \\
\hline Primary side of furnace transformer & 29.76 & 1.81 \\
\hline EAF & 0.313 & 64.12 \\
\hline Active power/MW & \multicolumn{2}{|c|}{90.25} \\
\hline Reactive power/MVar & \multicolumn{2}{|c|}{136.6} \\
\hline
\end{tabular}

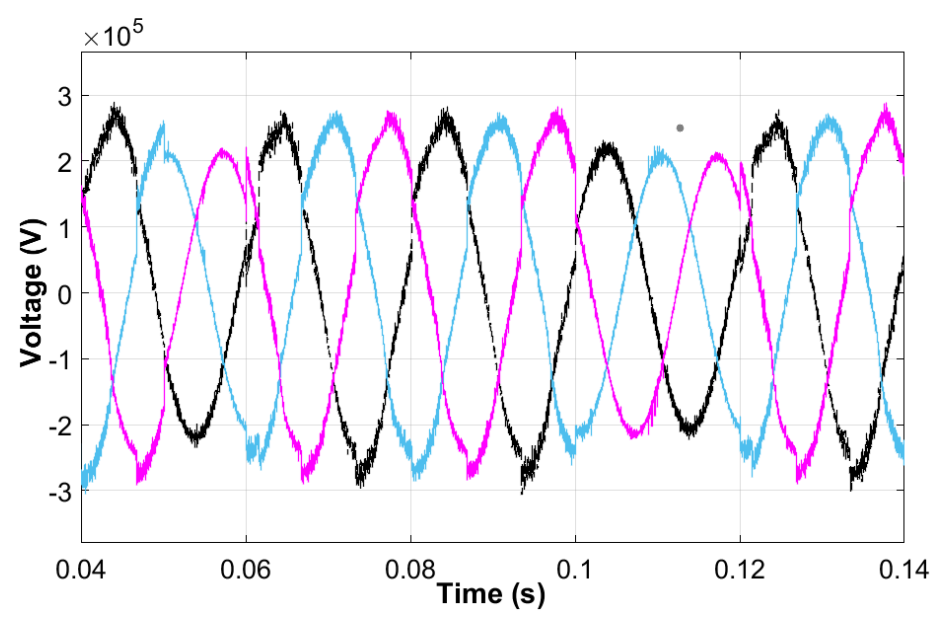

Figure 7 (a). The waveforms of voltage at PCC point when a three-phase short circuit occurs in an EAF

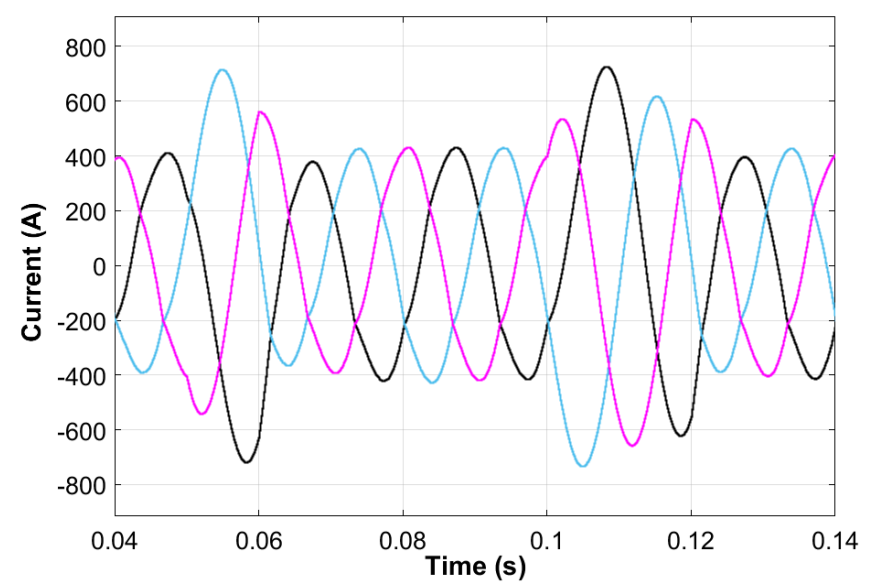

Figure 7(b). The waveforms of current at PCC point when a three-phase short circuit occurs in an EAF 


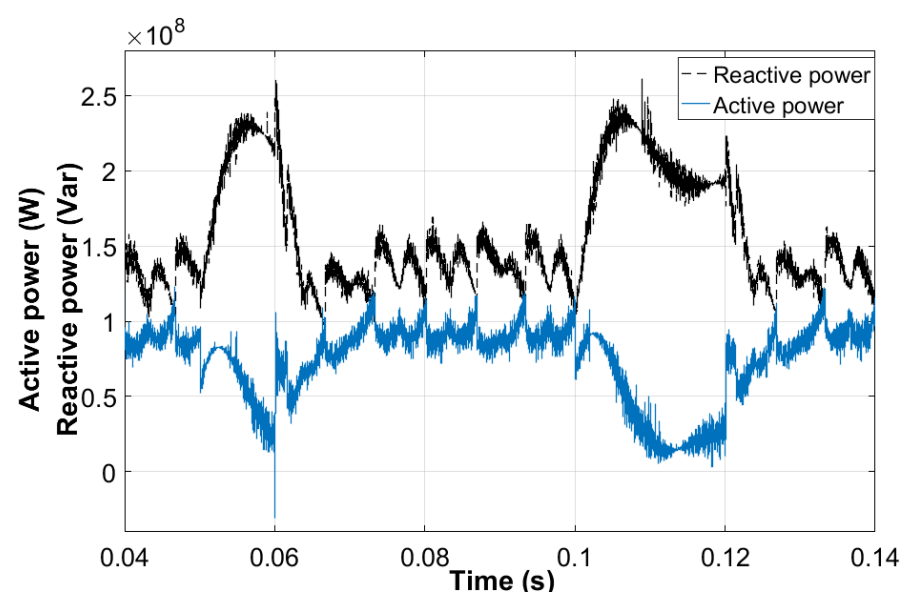

Figure 7(c). The waveforms of active power and reactive power at PCC point when a three-phase short circuit occurs in an EAF

Table 4. Simulation results when a three-phase short circuit occurs in an EAF

\begin{tabular}{cccc}
\hline Position & Short circuit current(kA) & Reactive power(MW) & Active power(MVar) \\
\hline secondary side of furnace transformer & 96.17 & & \\
$35 \mathrm{kV}$ side & 2.7 & 62.61 & 206.03 \\
$220 \mathrm{kV}$ side & 0.430 & & \\
\hline
\end{tabular}

\section{Discussion}

Comparing the simulation results of the three-phase short circuit of the electric arc furnace in Table 4 with the calculation results in Table 2, we can see that the calculated short-circuit current, reactive power and active power are not significantly different from the simulation results. Compared with the normal operation of the EAF, the reactive power and current are significantly increased when the three-phase short-circuit occurs, which verifies the previous analysis and calculation of the three-phase short-circuit of the EAF. It also shows that the model can effectively simulate the short-circuit situation of the EAF and conduct transient power quality analysis.

We can see from Figure 7 that when the three-phase short circuit of the EAF occurs, it will cause a large reactive power impact, which is nearly twice as high as that of the normal operation of the arc furnace, resulting in obvious voltage sag and current inrush at the PCC point. The short-circuit current reached 1.43 times the normal operating current, and the voltage dropped by $30.57 \%$. IEEE defines the short-term disturbance phenomenon that the rms voltage suddenly drops to $90 \% \sim 10 \%$ of the rated voltage and returns to normal after 0.5 cycle $\sim 1$ minute as the voltage sag. From the simulation results, it can be judged that the voltage drop caused by the electrode short circuit during the operation of the arc furnace is a voltage sag phenomenon.

\section{Conclusions}

(1) The EAF model established in the paper can reflect the operation characteristics of the EAF relatively simply and accurately. It does not need to solve the differential equation or too many preconditions and it has good portability. It can not only reflect the fluctuation of the EAF but also simulate the transient voltage of the EAF. The simulation results are not much different from the analysis and calculation results, and the characteristics of the electric arc furnace can be accurately simulated.

(2) A short-circuit of the electric arc furnace will cause a reactive power impact. The reactive power impact generated in the three-phase short circuit is twice that in the normal operation of the EAF, which causes the voltage sag of about $30 \%$ and current shock of 1.43 times at the PCC, which is very unfavorable to the power grid.

(3) The root cause of voltage swell and voltage sag at the PCC is the reactive power impact caused by the short circuit of the EAF. At present, the most effective method for 
the EAF voltage problem is reactive power compensation. The transient voltage problem of the EAF can also be improved by connecting the reactive power compensation device. The analysis of the voltage swell and voltage sag at PCC caused by different short circuit conditions of EAF provides reference for the transient power quality evaluation and dynamic reactive power compensation of EAF.

Funding: This research was funded by This work was Supported by the National Nature Science Foundation of China (51577157), and the Shaanxi Province Natural Science Basic Research Program (2019JM-357).

Conflicts of Interest: The authors declare no conflict of interest.

\section{References}

1. Lukasik, Z.; Olczykowski, Z. Estimating the impact of arc furnaces on the quality of power in supply systems. Energies 2020, 13, 1462.

2. Liu, Y. W.; Rau, S. H.; Wu, C. J. Improvement of power quality by using advanced reactive power compensation. IEEE Trans. Ind. Appl. 2018, 54, 18-24.

3. Naderipour, A.; Abdul-Malek, Z.; Gandoman, F. H. Optimal designing of static var compensator to improve voltage profile of power system using fuzzy logic control. Energy 2019, 192,

4. Li, M.; Li, W.; Ni, Y. et al. Power quality improvement based on an improved model of electric arc furnace and a nonlinear robust h-infinity control of statcom. 2016 International Conference on Intelligent Computation. Lanzhou, China,2 August 5 August 2016, 1129-1135.

5. Horton, R.; Haskew, T.A.; Burch, R.F., IV. A time-domain ac electric arc furnace model for flicker planning studies. IEEE Trans. Power Deliv. 2017, 24, 1450-1457.

6. Chang, G.W.; Lin, S.; Chen, Y.; Lu, H.; Chang, Y. An advanced EAF model for voltage fluctuation propagation study. IEEE Trans. Power Deliv. 2017, 32, 980-988.

7. Yu, J. H.; Kuan Hung Chen, Po Yi Huang, et al. Electric arc furnace voltage flicker analysis and prediction. IEEE Trans. on instrumentation and measurement 2011, 60, 3360-3368.

8. Cano-Plata, E.A.; Ustariz-Farfan, A.J.; Soto-Marin, O.J. Electric arc furnace model in distribution systems. IEEE Trans. Ind. Appl. 2015, 51, 4314-4320.

9. Xu, H. B.; Shao, Z. G.; Chen, F. X. Data-Driven compartmental modeling method for harmonic analysis - a study of the electric arc furnace. Energies 2019, 12, 4378.

10. Mehdi, T. E.; Behrooz, V. A new stochastic model of electric arc furnace based on hidden markov model: A study of its effects on the power system. IEEE Trans. Power Deliv. 2012, 27, 1893-1901.

11. Liu, X. H.; Yang, X. Y. Research on frequency domain method of harmonic analysis of electric system of arc furnace. Proceedings of the Chinese Society of Electrical Engineering 2006, 30-35.

12. Liu, X. H.; Zhao, G.; Yu, J. J. Simulation research on the influence of electric arc furnace nonlinear characteristics on power supply network. Proceedings of the Chinese Society of Electrical Engineering 2004, 34-38.

13. Alonso, M. A. P.; Donsion, M. P. An improved time domain arc furnace model for harmonic analysis. IEEE Trans. Power Syst. 2004, 19, 367-373.

14. Qi, B.R.; Xiao, X. N. Model and simulation of electric arc furnace for voltage fluctuation research. Transactions of China Electrotechnical Society 2000, 31-35.

15. Wang, Y. F.; Hao, L.; Hua, X. Study of a flexible power supply system with STATCOM based on a new dynamic EAF model, 2016 IEEE 8th International Power Electronics and Motion Control Conference (IPEMC 2016 - ECCE Asia). Hefei, China, 22 May-25 May 2016.

16. Wang, Y. F.; Jiang, J. G. A new type of AC arc furnace chaos model for power quality research. Proceedings of the Chinese Society of Electrical Engineering 2008, 106-110.

17. Wang, J.; Shu, H. C.; Lin, M.; Chen, C. Y. Modeling and simulation of AC arc furnace for dynamic power quality studies. Transactions of China Electrotechnical Sociaty 2003, 18, 53-58.

18. Wang, Y.; Mao, Z. Z.; Li, Y. AC arc furnace arc model for voltage fluctuation research. Power System Technology 2010, 34, 3640.

19. Banejad, M.; Hooshmand, R.; Torabian, E. M. Exponential-Hyperbolic Model for Actual Operating Conditions of Three Phase Arc Furnaces. American Journal of Applied Sciences 2009, 6,1539-1547.

20. Bhonsle, D. C.; Kelkar, R. B. Analyzing power quality issues in electric arc furnace by modeling. Energy 2016, 115, 830-839.

21. Chang, G.W.; Chen, C.I.; Liu, Y.J. A Neural-network-based method of modeling electric arc furnace load for power engineering study. IEEE Trans. Power Syst. 2010, 25, 138-146.

22. Gajic, D.; Savic-Gajic, I.; Savic, I.; Georgieva, O.; Gennaro, S.D. Modelling of electrical energy consumption in an electric arc furnace using artificial neural networks. Energy 2016,108, 132-139.

23. Chang, G. W.; Shi, M. F.; Chen, Y. Y.; Liang, Y. J. Hybrid wavelet transform and neural-network-based approach for modelling dynamic voltage-current characteristics of electric arc furnace. IEEE Trans. Power Deliv. 2014, 29, 815-824. 
24. Raul, G. S.; Javier, V. C.; Fernando, M. C.; Omar, L. G.; Jaime, O. A. Electric arc furnace modeling with artificial neural networks and arc length with variable voltage gradient. Energies 2017,10, 1424. 